\title{
Reaching a consensus of what an endoscopy service should be doing: A critical step on the road to excellence in endoscopy
}

\author{
Roland Valori MD FRCP, National Clinical Director of Endoscopy, England
}

\begin{abstract}
In recent decades, there have been major developments in health care and substantial improvements in clinical outcomes. However, there is still some way to go before we can say with confidence that all of our patients receive optimal care within our constraints of knowledge, technology and resources. In all health care systems, there is an unacceptable variation in care and, in many specialties, a lack of patient focus. This is particularly true for endoscopy, a diagnostic service that has evolved in a haphazard way, often in the backend of hospitals, and with insufficient planning to cope with new procedures and techniques, the burden of decontamination legislation and the huge expansion in demand.
\end{abstract}

Facilities and patient focus are significantly varied across and within nations: differences that largely reflect models of reimbursement. For example, the insured person in Australia is three times more likely to undergo a colonoscopy than an uninsured one (1). In Canada, there are significant differences in the provision of endoscopy within and outside hospital settings, and (from an external observer perspective) unacceptable differences in the training and outcomes of different professional groups (2). Systematic monitoring of quality indicators in Canada is not the rule, and even when they are monitored, it is not clear whether poor performance is identified and acted on.

The first step on the road to doing better is to be clear about what 'good' is. 'Good' can be defined in terms of outcomes (reduced mortality from colorectal cancer, low complication rates), outputs (adenoma detection rates or cecal intubation rates) or inputs (more training, use of carbon dioxide, WHO checklists, etc). The problem with outcomes is that they may not be evident for many years; they may be too infrequent to know for certain whether an individual or unit is underperforming; and they may occur after the patient has left the unit and, therefore, be very difficult to capture reliably. Another problem is that doctors tend to focus on what they regard as important and ignore - or dismiss as less important - patient-focused outcomes such as informed consent, privacy and dignity, and unambiguous information about the results of the procedure and next steps. We rely on surrogates of clinical outcomes such as adenoma detection rates and cecal intubation rates for the clinical outcomes and have not even measured the patient focused outcomes.

To create an excellent patient experience, and to ensure the best chance of achieving excellent clinical outcomes, attention must be devoted to getting the inputs right and broadening the range of outcomes we measure. In England, in 2004, an instrument known as the endoscopy Global Rating Scale (GRS) was developed. The GRS is a checklist of all the items opinion leaders (both nurse and doctor) believed should be in place to provide a high-quality, safe and patientcentred service (www.grs.nhs.uk). It is a consensus that was achieved systematically, but it was not a rigorous process, and it lacked a prior review of evidence. Modifications were made in the initial years following feedback from the service, thus, the consensus widened beyond opinion leaders. A patient feedback component ensured that services did not lose sight of the patient perspective. Services are required to self-assess twice a year, and 14 national censuses have been completed in seven years, with compliance rates of $96 \%$ to $100 \%$ in the past five years. This high acceptance is an indication that the service accepts the standards as being appropriate, and it is evident the GRS aids service improvement by providing a structured framework to make changes. Informal feedback indicates that endoscopy team leaders use the GRS to leverage their teams and their organizations to achieve improvements.

Other nations, including Canada, have tried and tested the GRS (3). In Canada, there are particular challenges to widespread adoption of the GRS or similar instruments that might achieve the same or similar goal. The obvious ones are the provincial nature of health care administration, the geography of the country, the variation in the nature and siting of facilities and, finally, the national governance of the service, which is largely led by physicians with relatively little input (compared with the United Kingdom) from surgeons or nurses. None of these challenges is insuperable, but before they can be addressed, there needs to be consensus on what 'good' looks like, and relying on a foreign version of 'good' is not enough to leverage widespread change when faced with so many difficulties.

The accompanying article in the present issue of the Canadian Journal of Gastroenterology (4) (pages 17-31) describes a consensus process aimed at filling this gap. A rigorous process has been adopted: identifying a wide range of possible indicators; a systematic review of the literature aimed at determining the extent to which the indicators were supported by an evidence base; online voting to remove redundant items; and, finally, a face-to-face meeting to reach consensus on what should be recommended. A wide range of stakeholders participated, and prior patient interviews informed the process. For most indicators, there was no evidence to support their use. However, the level of agreement was well in excess of $90 \%$ for the majority of indicators, and the strength of recommendation was mostly 'do it', with very few voting 'don't do it'. This is a triumph for common sense in the country that invented evidence-based medicine.

There remains a challenge for the leaders of Canadian endoscopy to implement these standards in clinical practice. They need to be clear about what they want to achieve and how this new consensus will help them achieve their goal. They must not be put off by the unique challenges of Canada. Working closely with surgeon and nurse leaders will be essential to ensure that all services and all professionals take ownership of the standards and commit to achieving them. Ideally, policymakers and public health officials should lend their support to implementation. There are some tough times ahead, but this excellent piece of work will certainly make things easier. If the standards can be achieved across Canada and in all health care settings, then Canadian endoscopists and their teams will have achieved excellence in endoscopy and equity of provision, and be able to demonstrate it. 


\section{REFERENCES}

1. Australian Government Department of Health and Ageing (2009) Report from the National Bowel Cancer Screening Program Quality Working Group: Improving Colonoscopy Services in Australia. <www.cancerscreening.gov.au/internet/screening/ publishing.nsf/Content/nbcs-imp-col-ser-0709-cnt> (Accessed on November 30, 2011).

2. Bressler B, Paszat LF, Chen Z, Rothwell DM, Vinden C, Rabeneck L. Rates of new or missed colorectal cancers after colonoscopy and their risk factors: A population-based analysis. Gastroenterology 2007;132:96-102.
3. de Jonge V, Sint Nicolaas J, Lalor EA, et al. A prospective audit of patient experiences in colonoscopy using the Global Rating Scale: A cohort of 1187 patients. Can J Gastroenterol 2010;24:607-13.

4. Armstrong A, Barkun A, Bridges R, et al; on behalf of the Canadian Association of Gastroenterology Safety and Quality Indicators in Endoscopy Consensus Group. Can J Gastroenterol 2012;1:17-31. 


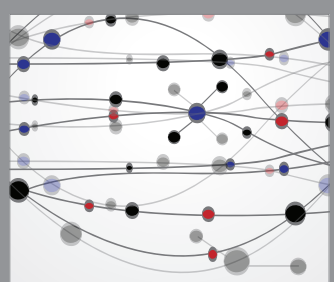

The Scientific World Journal
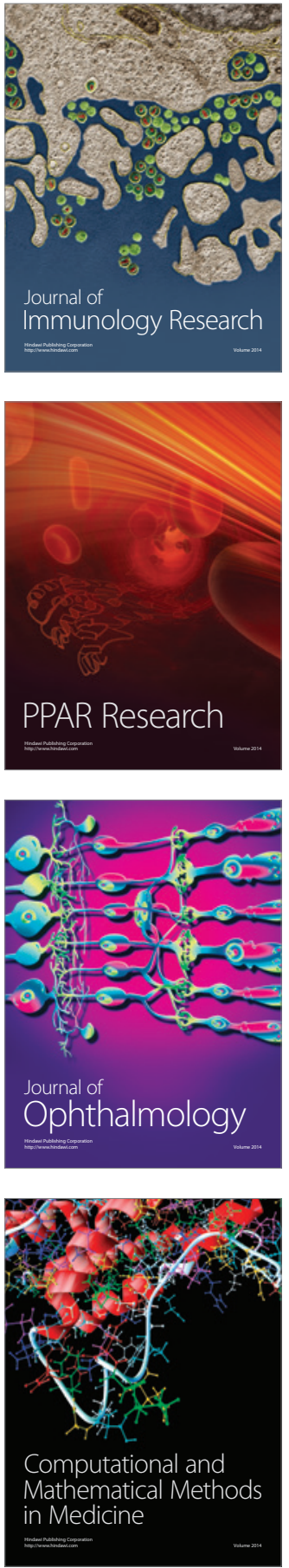

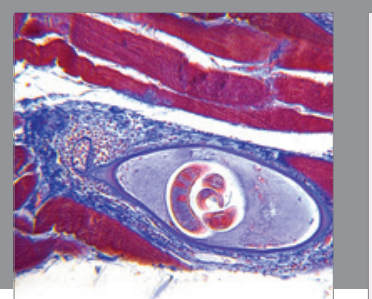

Gastroenterology Research and Practice

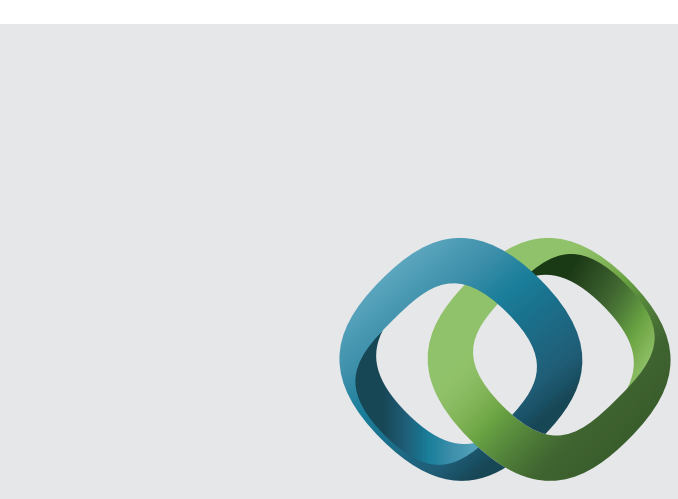

\section{Hindawi}

Submit your manuscripts at

http://www.hindawi.com
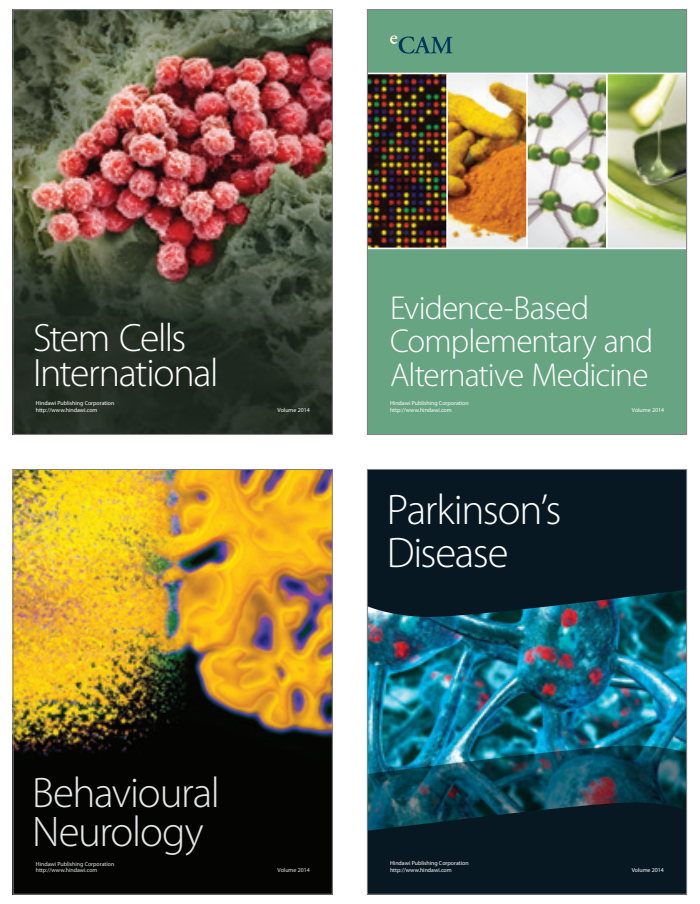
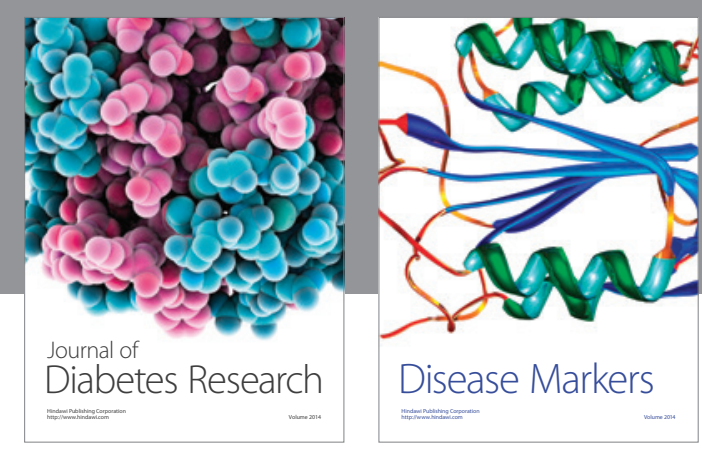

Disease Markers
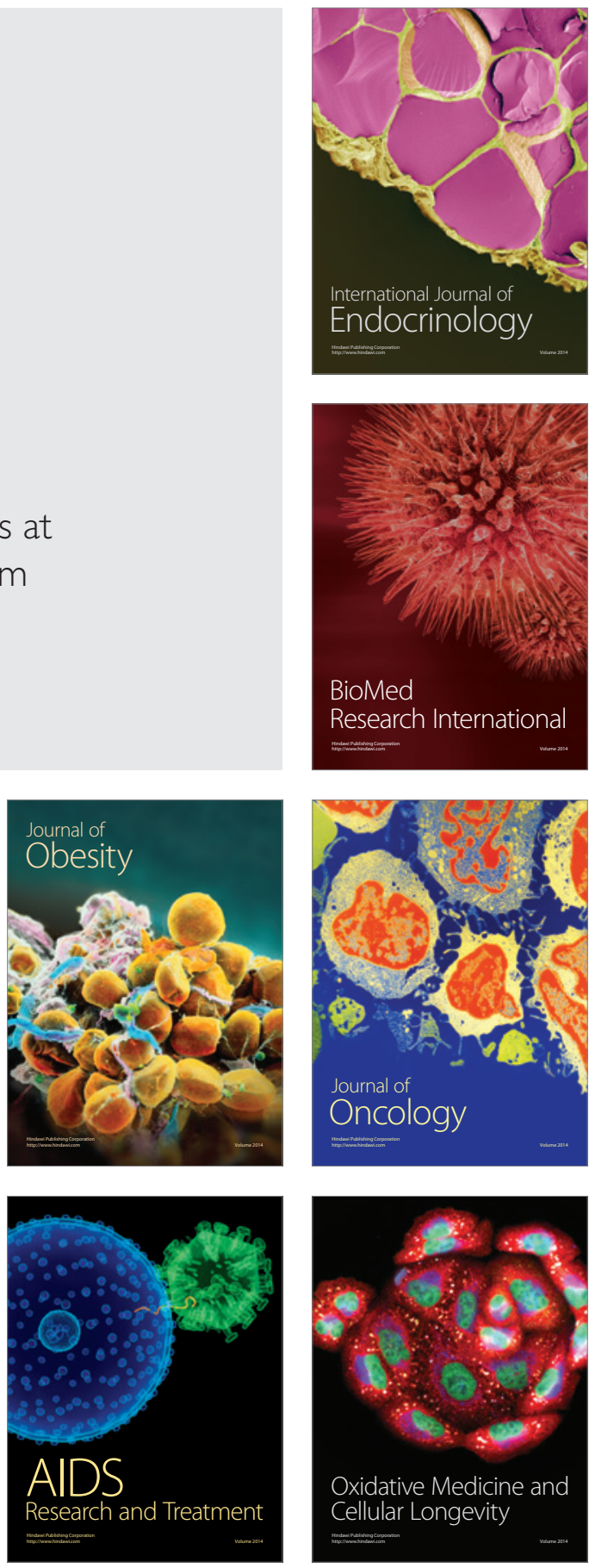